\title{
PENGARUH PROGRAM CSR INTERNAL DAN LINGKUNGAN KERJA FISIK TERHADAP KEPUASAN KERJA KARYAWAN PADA PT ALEX PUTRA GROUP DIKOTA CILEGON
}

\author{
MiftahulFalaah, Anizir Ali Murad', Deni Sunaryo² \\ miftahfalaah@gmail.com, anizira@yahoo.co.id, denisunaryomm@gmail.com
}

FakultasEkonomidanBisnis, UniversitasSerang Raya

\begin{abstract}
ABSTRAK
Penelitian inibertujuanuntuk mengetahuipengaruh pada setiap variabel dependen Pengaruh Program CSR Internal $\left(\mathrm{X}_{1}\right)$ dan Lingkungan Kerja Fisik $\left(\mathrm{X}_{2}\right)$ terhadap variabel terikat Kepuasan Kerja Karyawan (Y).Dalam penelitian ini data dikumpulkan melalui metode kuesioner terhadap 39 orang responden yang bekerja di PT. Alex Putra GroupCilegondan menggunakan sample jenuh. Analisis yang digunakan adalah analisis linier berganda dengan menggunakan teknik analisis data yang telah memenuhi uji validitas, uji reliabilitasdanujiasumsiklasik,sehingga menghasilkan persamaan regresi sebagai berikut : $\mathbf{Y}=\mathbf{1 6 , 7 3 6}+\mathbf{0 , 4 0 6} \mathbf{X}_{\mathbf{1}}+\mathbf{0 , 7 3 1} \mathbf{X}_{\mathbf{2}}+\mathbf{e}$, Hasil analisis mendapatkan bahwa kedua variabel Program Corporate Social Responsibility Internal dan Lingkungan Kerja Fisik memiliki pengaruh yang signifikan terhadap Kepuasan Kerja Karyawan. Angka adjusted $R$ Squaresebesar 0.150 menunjukan bahwa 15 persen variasi Kepuasan Kerja Karyawan bisa dijelaskan oleh kedua variabel dependen yang digunakan dalam persamaan regresi. Sedangkan sisanya 85 persen dijelaskan oleh variabel lain diluar kedua variabel yang digunakan dalam penelitian ini.
\end{abstract}

Kata Kunci : program corporate social responsibility internal, lingkungan kerja fisik, dan kepuasan kerja karayawan

\begin{abstract}
The purpose of this risetto determine the effect on each dependent variable Effect of CSR Internal $\left(X_{1}\right)$ and Physical Work Environment $\left(X_{2}\right)$ on the dependent variable Employee Job Satisfaction (Y). In this study data was collected through a questionnaire method for 39 respondents who worked at PT. Alex Putra Group Cilegon. The analysis used was multiple linear analysis using data analysis techniques that have fulfilled the validity, reliability test and classical assumption test, so as to produce the regression equation as follows: $Y=16,736+0,406 X_{1}+0,731 X_{2}+e$, The results of the analysis found that both the Internal Corporate Social Responsibility Program variables and the Physical Work Environment had a significant influence on Employee Job Satisfaction. The adjusted $R$ Square figure of 0.150 shows that 15 percent variation in Employee Job Satisfaction can be explained by the two dependent variables used in the regression equation. While the remaining 85 percent is explained by other variables outside the two variables used in this study.
\end{abstract}

Keywords: internal corporate social responsibility program, physical work environment, and employee job satisfaction 


\section{PENDAHULUAN}

Kemajuan organisasi dan badan hukum yang sangat pesat pada saat ini tidak lepas dari pentingnya unsur sumber daya manusia di dalam organisasi, karena sumber daya manusia adalah salah satu faktor pelaku dari semua kegiatan yang ada dalam organisasi. Sumber daya manusia yang sangat penting dan sangat menentukan, karena jika tidak ada sumber daya manusia yang handal maka akan sulit bagi organisasi dalam mencapai tujuannya.

Kepuasan kerja memilki pengertian sebagai tingkat kesenangan atau rasa puas dalam bekerja sehingga pekerjaan memilki sense of belongin kepada pekerjaan, loyal dan memiliki rasa aman dalam bekerja, akan tetapi pencapaian kinerja karyawan cenderung menurun dikarenakan kurangnya kepedulian dari pihak perusahaan, kemudianPemberdayaan karyawan yang masih perlu diperhatikan.Kurangnya konsistensi pihak perusahaan dalam mengambil keputusan hak bagi karyawan

Bila lingkungan kerja cukup nyaman dan komunikasi di dalamnya berjalan lancar, maka kinerja yang dihasilkan pun tentu akan maksimal. Namun sebaliknya, apabila lingkungan kerja tidak nyaman, dipenuhi dengan masalah dan persaingan tidak sehat, maka akan tercipta kejenuhan dari para karyawan yang pada akhirnya akan menurunkan motivasi kerja mereka dan menciptakan ketidak puasan dalam bekerja, oleh sebab itu lingkungan kerja segala sesuatu yang ada disekitar karyawan pada saat bekerja, baik berbentuk fisik yang langsung atau tidak langsung yang dapat mempengaruhi saat bekerja.

CSR dapat diartikan sebagai komitmen pemberdayaan sosial untuk mempertanggungjawabkan dampak operasi dalam dimensi sosial, serta menjaga agar dampak tersebut menyumbang manfaat kepada masyarakat dan perusahaannya. Kurangnya konsistensi pihak perusahaan dalam mengambil keputusan hak bagi karyawan beresiko adanya mogok kerja akibat adanya kekecewaan karyawan pada perusahaan.

\section{Tujuan Penelitian}

1. Untuk mengetahui pengaruh program corporate social responsibility internal terhadap kepuasan karyawan.

2. Untuk mengetahui pengaruh lingkungan kerja terhadap kepuasan karyawan.

3. Untuk mengetahui pengaruh program corporate social responsibility internal dan lingkungan kerja terhadap kepuasan karyawan pada PT. Alex Puta Group di Kota Cilegon.

\section{LANDASAN TEORI DAN PENGEMBANGAN HIPOTESIS}

\section{Pengertian Kepuasan Kerja}

Kepuasan menunjukkan kemampuan organisasi dalam memenuhi kebutuhan karyawannya. Pengertian kepuasan telah dikemukakan oleh beberapa ahli. Menurut David dan Newstorm (2008: 105) mengatakan kepuasan kerja adalah seperangkat perasaan pegawai tentang menyenangkan atau tidaknya pekerjaan karyawan. Menurut Handoko (2008: 193) mengatakan bahwa kepuasan kerja adalah keadaan emosional yang menyenangkan dan tidak menyenangkan dengan mana para karyawan memandang pekerjaan mereka. 
Menurut Robbins (2006:76) bahwa faktor - faktor yang mendorong kepuasan kerja adalah : ganjaran yang pantas, pekerjaan itu sendiri, rekan kerja yang mendukung,

Dalam Panggabean (2004:130) faktor-faktor yang perlu diperhatikan agar dapat menimbulkan kepuasan kerja pada diri seorang karyawan yaitu :

1. Monetery/non-monetery, yaitu adanya penghargaan terhadap kinerjakaryawan dari segi monetery misalnya gaji dan upah dan non-monetery misalnya promosi dan lainlain.

2. Karakteristik pekerjaan (job characteristics), yaitu berkaitan dengan pekerjaan itu sendiri dimana ia berkaitan dengan cara bagaimana karyawan menilai tugas-tugas yang ada dalam pekerjaannya.

3. Karakteristik kerja (work characteristics), merupakan faktor-faktor yang diduga dapat membantu atau menghalangi karyawan dalam pelaksanaan tugas-tugasnya.

4. Karakteristik individu yang dianutnya, yaitu sikap dan perilaku yang ada pada individu akibat dari nilai-nilai.

H3:Variabel Program CSR Internal $\left(\mathrm{X}_{1}\right)$ danLingkunganKerjaFisik $\left(\mathrm{X}_{2}\right)$ secarabersamasamamemilikipengaruh yang signifikanterhadapkinerjakaryawan (Y). Dengannilai $\mathrm{F}$ sebesar 4,363

\section{Corporate Social Responbility (CSR) INTERNAL}

Tanggung jawab sosial perusahaan (Corporate Social Responsibility)Secara umum merupakan kontribusi menyeluruh dari dunia usaha terhdap pembangunan berkelanjutan dengan mempertimbangkan dampak ekonomi, sosial, dan lingkungan dari kegiatannya. CSR terdiri dari dua bagian yaitu CSR internal dan CSR eksternal. Internal maksudnya tanggung jawab sosial perusahaan terhadap orang-orang yang berada di dalam perusahaan seperti supervisor, karyawan pelaksana, manajer, pemegang saham dan direksi perusahaan. Eksternal maksudnya tanggung jawab sosial perusahaan terhadap orang-orang yang tidak berkaitan langsung dengan perusahaan seperti pemerintah, pelanggan, komunitas, masyarakat dan pemasok.

Pohan (2008:27) yaitu Corporate Social Responsibility internal adalah tanggung jawab moral perusahaan terhadap karyawan dengan membina hubungan kerja yang baik di berbagai tingkatan kedudukan mulai dari bawah sampai ketingkat atasan, menciptakan keterbukaan dari masalah informasi peraturan perusahaan seluruhnya yang berkaitan dengan kemajuan dan kemunduran perusahaan.

Petkoski dan Twose (2003). CSR sebagai komitmen bisnis yang berperan untuk mendukung pembangunan ekonomi, bekerja sama dengan karyawan dan keluarganya, masyarakat lokal dan masyarakat luas untuk meningkatkan mutu hidup mereka dengan berbagai carayang menguntungkan bagi bisnis dan pembangunan. Didalam Green Paper Komisi Masyarakat Eropa dinyatakan bahwa, kebanyakan definisi tanggung jawab sosial korporat menunjukan sebuah konsep tentang pengintegrasian, kepedualian terhadap 
masalah sosial dan lingkungan hidup kedalam operasi bisnis perusahaan dan interaksi sukarela antara perusahaan dan stakeholdernya.

H1: Hasil analisis mengenai pengaruh Program CSR Internal menunjukan bahwa hasil analysis memiliki hubungan yang positif dan signifikan terhadap kepuasan Kerja Karyawan yang ditunjukan dengan koefisien variabel dimana pengaruh Program CSR Internal $\left(\mathrm{X}_{1}\right)$ bertanda positif dan signifikan terhadap Kepuasan Kerja Karyawan (Y) dengan nilai $\mathrm{t}_{\text {hitung }}$ sebesar 2.165 .

\section{Lingkunga KerjaFisik}

Menurut Sedarmayanti (2007:21), "Lingkungan kerja fisika adalah semua keadaan berbentuk fisik yang terdapat disekitar tempat kerja yang dapat mempengaruhi karyawan baik secara langsung maupun tidak langsung. Ada pun dimensi yang digunakan yaitu lingkungan kerja fisik dengan melihat indikatornya yaitu ruangan, sirkulasi udara, dan kebersihan. Lingkungan kerja fisik dapat dibagi dalam dua kategori, yakni:

1. Lingkungan yang langsung berhubungan dengan karyawan (Seperti: pusat kerja, kursi, meja).

2. Lingkungan perantara atau lingkungan umum dapat juga disebut lingkungan kerja yang mempengaruhi kondisi manusia, misalnya temperature, kelembaban, sirkulasi udara, pencahayaan, kebisingan, getaran mekanis, bau tidak sedap, warna dan lainlain. Untuk dapat memperkecilkan pengaru hlingkungan fisik terhadap karyawan, maka langkah pertama adalah harus mempelajari manusia, baik mengenai fisik dan tingkah lakunya mau pun mengenaifisiknya, kemudian digunakan sebagai dasar memikirkan lingkungan fisik yang sesuai.

H2 : Hasil analisis mengenai pengaruh Lingkungan Kerja Fisik $\left(\mathrm{X}_{2}\right)$ memiliki hubungan yang positif dan signifikan terhadap Kepuasan Kerja Karyawan (Y) yang ditunjukan dengan koefisien variabel, dimana pengaruh Lingkungan Kerja Fisik bertanda positif dan memiliki pengaruh yang signifikan terhadap Kepuasan Kerja Karyawan dengan nilai $t$ hitung sebesar 2,361 .

\section{METODE PENELITIAN}

Jenis penelitian yang digunakan adalah penelitian deskriptif yaitu penelitian yang dilakukan dengan tujuan utama untuk memberikan gambaran atau deskripsi tentang suatu keadaan secara objektif.Penelitian ini dilakukan di PT. Alex Putra Group yang berada di Jl. Lingkar Selatan KM 3 Desa Kalitimbang Kecamatan Cibeber Kota Cilegon. Waktu penelitian dimulai dari Bulan Februari 2017 sampai dengan selesai.

Skala pengukuran yang digunakan adalah skala interval, karena skala interval tidak hanya mengelompokkan individu menurut kategori tertentu dan menentukan urutan kelompok, namun juga mengukur besaran perbedaan preferensi antar individu (Sekaran, 2006:18). Sedangkan teknik pengukuran skala yang digunakan dalam penelitian ini untuk mengukur variabel adalah skala diferensial semantik, 


\begin{tabular}{ccccccc}
1 & 2 & 3 & 4 & 5 & 6 & 7 \\
\hline Sangat & Tidak & Kurang & Netral & Puas & Sangat & Sangat \\
Tidak & Puas & Puas & & & Puas & Puas \\
Puas & & & & & & Sekali
\end{tabular}

yaitu metode penilaian dengan menggunakan 7 butir yang di bentuk dalam satu garis kontinyu yang menyatakan secara verbal 2 kutub penilaian yang ekstrem.Populasi pada penelitian ini adalah seluruh karyawan padaPT. Alex Putra Group Cilegon yang berjumlah 39 orang.

Teknik sampling yang digunakan dalam penelitian ini adalah teknik sampling jenuh, menurut Sugiyono (2012:126) menyatakan bahwa:Sampling jenuh adalah teknik penentuan sampel bila semua anggota populasi digunakan sebagai sampel. Hal ini sering dilakukan bila jumlah populasi relatif kecil, kurang dari 30 orang

Peneliti menggunakan teknik pengumpulan data terdiri atas observasi, angket, wawancara, dokumentasi dan kepustakaan. Teknik analisis data dalam penelitian kuantitatif menggunakan statistik pada penelitian ini menggunakan jenis analisis data statistik inferensial, adalah teknik statistik yang digunakan untuk menganalisis data sampel dan hasilnya deiberlakukan untuk populasi. Statistik ini cocok apabila sampel diambil dari populasi yang jelas, dan teknik pengambilan sampel dari populasi tersebut dilakukan secara random.

\section{Analisis Data}

\section{Analisis Regresi Linear Berganda}

Melalui analisis regresi linear berganda dapat diketahui seberapa besar koefisien regresi variabel CSR Internal (X1) dan variabel Lingkungan Kerja Fisik (X2) terhadap variabel Kepuasan Kerja Karyawan (Y) pada perusahaan. Hasil perhitungan regresi linear berganda dapat dilihat pada tabel 4.19 berikut :

\section{Perhitungan Koefisien Regresi Linear berganda}

Coefficients $^{\mathrm{a}}$

\begin{tabular}{|c|c|c|c|c|c|}
\hline \multirow[b]{2}{*}{ Model } & \multicolumn{2}{|c|}{$\begin{array}{c}\text { Unstandardized } \\
\text { Coefficients }\end{array}$} & \multirow{2}{*}{$\begin{array}{c}\text { Standardized } \\
\text { Coefficients } \\
\text { Beta }\end{array}$} & \multirow[b]{2}{*}{$\mathrm{t}$} & \multirow[b]{2}{*}{ Sig. } \\
\hline & B & Std. Error & & & \\
\hline 1 (Constant) & 16,736 & 4,775 & & 3,505 & 001 \\
\hline PROG.CSR_INTERNAL & 406 & 188 & 329 & 2,165 & 037 \\
\hline LING.KERJA_FISIK & ,731 & ,309 & 359 & 2,361 & 024 \\
\hline
\end{tabular}

a. Dependent Variable: KEP.KERJA_KWN

\section{Sumber : Pengolahan data SPSS 23.0}

Hasil analisis regresi linear berganda pada tabel 4.19 diatas diperoleh persamaan sebagai berikut :

$$
\begin{aligned}
& Y=a+b_{1} X_{1}+b_{2} X_{2}+e \\
& Y=16,736+0,406 X_{1}+0,731 X_{2}+e
\end{aligned}
$$

Dimana :

$\mathrm{Y}=$ Kepuasan Kerja Karyawan

$\mathrm{X}_{1}=$ CSR Internal

$\mathrm{X}_{2} \quad$ = Lingkungan Kerja Fisik

$\mathrm{a}=$ Konstanta e = Standar Error 
Berdasarkan persamaan tersebut dapat diketahui ;

1. Konstanta (a) $=16,736$ menunjukan nilai konstan, jika nilai variabel bebas (CSR Internal dan Lingkungan Kerja Fisik) $=0$ maka Kepuasan Kerja Karyawan (Y) akan sebesar 16,736 .

2. Koefisien regresi variabel CSR Internal sebesar 0,406 menunjukan bahwa variabel CSR Internal $\left(\mathrm{X}_{1}\right)$ bernilai signifikan terhadap Kepuasan Kerja Karyawan (Y). Dengan kata lain, Jika variabel CSR Internal ditingkatkan sebesar 1 (satuan) maka Kepuasan Kerja Karyawan akan meningkat sebesar 0,406 dengan asumsi variabel lainya tetap.

3. Koefisien regresi variabel Lingkungan Kerja Fisik adalah sebesar 0,731 menunjukan bahwa variabel Lingkungan Kerja Fisik $\left(\mathrm{X}_{2}\right)$ bernilai signifikan terhadap kepuasan kerja karyawan (Y). Dengan demikian jika variabel Lingkungan Kerja Fisik ditingkatkan 1 (satu) maka Kepuasan Kerja Karyawan juga meningkat sebesar 0,731 dengan asumsi variabel lainya tetap.

\section{Pengujian Hipotesis}

\section{Uji Signifikansi Parsial (Uji t)}

Hasil uji parsial (Uji t) menunjukan seberapa besar hubungan dan pengaruh masingmasing variabel CSR Internal $\left(\mathrm{X}_{1}\right)$ dan variabel Lingkungan Kerja Fisik $\left(\mathrm{X}_{2}\right)$ secara parsial terhadap Kepuasan Kerja Karyawan pada PT. Alex Putra Group di Kota Cilegon. Hasil uji t dapat dilihat pada tabel berikut :

\section{Hasil Uji Signifikansi Parsial (Uji t)}

\begin{tabular}{|l|r|r|r|r|r|}
\hline & \multicolumn{2}{|c|}{$\begin{array}{c}\text { Unstandardized } \\
\text { Coefficients }\end{array}$} & $\begin{array}{c}\text { Standardized } \\
\text { Coefficients }\end{array}$ & & \\
\cline { 2 - 4 } Model & \multicolumn{1}{|c|}{ B } & Std. Error & Beta & T & Sig. \\
\cline { 2 - 6 } 1 (Constant) & 16,736 & 4,775 & & 3,505 &, 001 \\
PROG.CSR_INTERNAL &, 406 &, 188 &, 329 & 2,165 &, 037 \\
LING.KERJA_FISIK &, 731 &, 309 &, 359 & 2,361 &, 024 \\
\hline
\end{tabular}

a. Dependent Variable: KEP.KERJA_KWN

\section{Sumber : Pengolahan data SPSS 23.0}

Berdasarkan Tabel hasil uji t diatas, diketahui bahwa :

1. Nilai Signifikansi untuk pengaruh Variabel CSR Internal $\left(\mathrm{X}_{1}\right)$ terhadap Kepuasan Kerja Karyawan (Y) adalah sebesar 0,037 < dari 0,05 dan nilai t hitung 2,165> dari t tabel 2,028 maka dapat disimpulkan bahwa $\mathrm{H}_{1}$ diterima dan $\mathrm{H}_{\mathrm{o}}$ ditolak atau yang berarti terdapat pengaruh variabel $\mathrm{X}_{1}$ terhadap $\mathrm{Y}$.

2. Nilai signifikansi untuk pengaruh Variabel Lingkungan Kerja Fisik $\left(\mathrm{X}_{2}\right)$ terhadap Kepuasan Kerja Karyawan (Y) adalah sebesar 0,024 < dari 0,05 dan nilai t hitung 2,361 > dari t tabel 2,028 maka dapat disimpulkan bahwa $\mathrm{H}_{2}$ diterima dan $\mathrm{H}_{\mathrm{o}}$ ditolak atau yang berarti terdapat pengaruh variabel $\mathrm{X}_{2}$ terhadap $\mathrm{Y}$. 
3. Dari Tabel diatas dapat diketahui bahwa variabel Lingkungan Kerja Fisik $\left(\mathrm{X}_{2}\right)$ lebih dominan dibandingkan dengan variabel CSR Internal $\left(\mathrm{X}_{1}\right)$, hal ini karena pekerjaan lebih banyak berada di lingkungan kerja fisik perusahaan. Sehingga perusahaan harus menyesuaikan apa yang selalu dibutuhkan demi adanya kenyamanan dalam bekerja dan meningkatkan produktivitas perusahaan.

\section{Uji Signifikansi Simultan (Uji F)}

Hasil uji simultan (Uji F) menunjukan seberapa besar pengaruh variabel CSR Internal $\left(\mathrm{X}_{1}\right)$ dan variabel Lingkungan Kerja Fisik $\left(\mathrm{X}_{2}\right)$ secara bersama-sama atau serempak terhadap variabel Kepuasan Kerja Karyawan (Y) pada PT. Alex Putra Group di Kota Cilegon. Hasil uji F dapat dilihat pada tabel berikut :

Hasil Uji Signifikansi Simultan (Uji F) ANOVA $^{\mathrm{a}}$

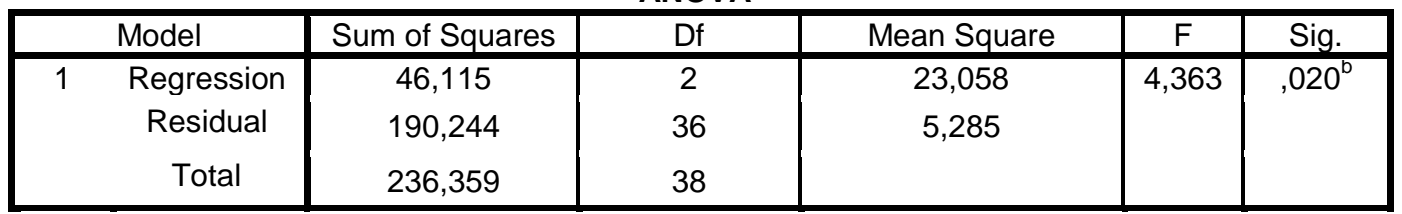

a. Dependent Variable: KEP.KERJA_KWN

b. Predictors: (Constant), LING.KERJA_FISIK, PROG.CSR_INTERNAL

\section{Sumber : Pengolahan data SPSS 23.0}

Berdasarkan tabel diatas, dapat diketahui nilai $\mathrm{F}$ hitung adalah sebesar 4,363 dan nilai $\mathrm{F}$ tabel 3,25. Dengan demikian nilai signifikansi untuk pengaruh variabel CSR Internal $\left(\mathrm{X}_{1}\right)$ dan variabel Lingkungan Kerja Fisik $\left(\mathrm{X}_{2}\right)$ secara simultan terhadap variabel Kepuasan Kerja Karyawan (Y) adalah sebesar 0,020 < 0,05 dan nilai $\mathrm{F}$ hitung 4,363 $>3,25$ sehingga dapat disimpulkan bahwa $\mathrm{H}_{3}$ diterima dan $\mathrm{H}_{\mathrm{o}}$ ditolak yang berarti terdapat pengaruh $\mathrm{X}_{1}$ dan $\mathrm{X}_{2}$ secara simultan terhadap Y.

\section{Uji Koefisien Determinasi $\left(\mathbf{R}^{2}\right)$}

Dalam penelitian ini dapat diketahui seberapa besar kontribusi variabel CSR Internal $\left(\mathrm{X}_{1}\right)$ dan variabel Lingkungan Kerja Fisik $\left(\mathrm{X}_{2}\right)$ terhadap variabel Kepuasan Kerja Karyawan (Y). Melalui Koefisien Determinasi $\left(\mathrm{R}^{2}\right)$ dengan menggunakan program SPSS (Statistical Product dan Service Solution) versi 23.0 For Windows dapat dilihat pada Tabel berikut :

\section{Hasil Uji Koefisien Determinasi $\left(\mathbf{R}^{2}\right)$}

\begin{tabular}{|l|r|r|r|c|}
\hline \multicolumn{7}{|c|}{ Model Summary $^{\mathbf{b}}$} \\
\hline Model & $\mathrm{R}$ & $\mathrm{R}$ Square & \multicolumn{1}{|c|}{$\begin{array}{c}\text { Adjusted R } \\
\text { Square }\end{array}$} & $\begin{array}{c}\text { Std. Error of the } \\
\text { Estimate }\end{array}$ \\
\hline 1 &, $442^{\mathrm{a}}$ &, 195 &, 150 & 2,29881 \\
\hline
\end{tabular}

a. Predictors: (Constant), LING.KERJA_FISIK, PROG.CSR_INTERNAL

b. Dependent Variable: KEP.KERJA_KWN

\section{Sumber : Pengolahan data SPSS 23.0}

Berdasarkan hasil uji koefisien determinasi $\left(\mathrm{R}^{2}\right)$ pada tabel diatas terlihat bahwa variabel CSR Internal $\left(\mathrm{X}_{1}\right)$ dan variabel Lingkungan Kerja Fisik $\left(\mathrm{X}_{2}\right)$ memiliki kontribusi positif sebesar 0,195 (19,5\%) terhadap variabel Kepuasan Kerja Karyawan (Y). Sedangkan sisanya 
sebesar 80,5 \% dipengaruhi oleh faktor-faktor lainya yang tidak diikut sertakan dalam penelitian ini.

\section{HASIL ANALISIS DAN PEMBAHASAN}

\section{Pengaruh CSR Internal Dan Lingkungan Kerja Fisik Terhadap Kepuasan Kerja Karyawan Pada PT. Alex Putra Group Di Kota Cilegon}

Dari hasil signifikansi uji simultan (Uji F) terlihat bahwa secara bersama-sama atau simultan variabel CSR Internal $\left(\mathrm{X}_{1}\right)$ dan variabel Lingkungan Kerja Fisik $\left(\mathrm{X}_{2}\right)$ berpengaruh positif dan signifikan terhadap variabel Kepuasan Kerja Karyawan (Y) dimana nilai F hitung sebesar $(4,363)>$ dari nilai $\mathrm{F}$ tabel $(3,25)$ dengan tingkat signifikansi sebesar 0,020<0,05. Berarti koefisien signifikan secara statistik CSR Internal dan Lingkungan Kerja Fisik secara bersama-sama berpengaruh positif terhadap Kepuasan Kerja Karyawan. CSR Internal hendaknya menyesuaikan keadaan profit tanpa melihat manfaat CSR yang berhubungan dengan karyawan terkait aktivitasnya yang secara langsung terhubung pada fisik, karena karyawan menemukan dirinya tersebut ketika dalam bekerja dan berorganisasi.

\section{Pengaruh CSR Internal Terhadap Kepuasan Kerja Karyawan}

Dari hasil uji signifikansi parsial (Uji t) terlihat bahwa secara parsial terdapat pengaruh yang positif dan signifikan antara variabel CSR Internal $\left(\mathrm{X}_{1}\right)$ terhadap variabel Kepuasan Kerja Karyawan (Y) dengan nilai signifikansi sebesar 0,037 <0,05 dan nilai t hitung 2,165 > t tabel 2,028. Maka dapat disimpulkan bahwa secara parsial variabel CSR Internal $\left(\mathrm{X}_{1}\right)$ berpengaruh positif dan signifikan terhadap variabel Kepuasan Kerja Karyawan (Y). Hal ini menunjukan bahwa program CSR Internal yang diterapkan secara umum berdampak positif dan signifikan terhadap Kepuasan Kerja Karyawan khususnya :

1. Adanya kebijakan perusahaan dalam mendukung pembangunan ekonomi masyarakat, kebijakan ini membantu masyarakat untuk berkembang dalam mengelola perekonomian mereka agar semakin maju, sehingga karyawan dan masyarakat dalam segi kebutuhanya dapat sedikit terpenuhi. Terlebih pada saat era globalisasi yang tinggi ini persaingan ekonomi yang pesat membuat perusahaan harus lebih bertanggung jawab terhadap kebutuhan karyawan dan masyarakat yang lebih modern.

2. Adanya kebijakan perusahaan dalam bekerja sama dengan karyawan dan keluarganya, dengan adanya kebijakan tersebut karyawan merasa terbantu karena rasa tanggung jawab perusahaan membantu karyawan bukan hanya saat bekerja saja melainkan sikap kepedulian tersebut diberikan kepada keluarganya sebagai bentuk tanggung jawab sosial perusahaan sehingga menimbulkan rasa loyalitas karyawan terhadap perusahaan ataupun jalinan silaturahmi antar karyawan juga tetap terjaga hingga jangka panjang.

3. Kebijakan perusahaan dalam meningkatkan mutu dan kualitas hidup masyarakat lokal dan masyarakat luas, dengan adanya kebijakan tersebut maka mutu dan kualitas hidup masyarakat meningkat dan menjadi tenaga kerja yang produktif dan berkualitas, kemudian, karena adanya rasa yang timbul pada pribadi mereka yang tertanam akibat dari kepedulian dan tanggung jawab perusahaan yang sudah diberikan atau disalurakan sehinnga berdampak baik pula pada produktifitas perusahaan yang meningkat dan profitablitas yang naik. 


\section{Pengaruh Lingkungan Kerja Fisik Terhadap Kepuasan Kerja Karyawan}

Dari hasil uji signifikansi parsial (Uji t) terlihat bahwa secara parsial terdapat pengaruh yang positif dan signifikan antara variabel Lingkungan Kerja Fisik $\left(\mathrm{X}_{2}\right)$ terhadap Kepuasan Kerja Karyawan (Y) sebesar 0,024 $<0,05$ dan nilai t hitung 2,361 > dari t tabel 2,208 dengan demikian berdasarkan uji hipotesis $\mathrm{H}_{2}$ diterima dan $\mathrm{H}_{\mathrm{o}}$ ditolak. Hal ini menunjukan bahwa kondisi Lingkungan Kerja Fisik perusahaan telah berhasil meningkatkan Kepuasan Kerja Karyawan khususnya mengenai :

1. Penempatan kursi pada ruang kerja sudah sesuai dan tersusun rapih, sehingga karyawan merasa nyaman ketika dalam bekerja dimana setiap kali karyawan masuk kerja penempatan kursi sudah pada tempatnya tanpa perlu repot-repot membersihkan dan merapihkanya lagi, hal ini memberikan rasa motivasai bahwa setiap karyawan sudah diberikan kenyamanan dalam bekerja maka karyawan tersebut harus memiliki kontribusi yang baik agar terciptanya tujuan perusahaan.

2. Penempatan meja pada ruang kerja sudah sesuai dengan fungsinya, tempat kerja yang nyaman merupakan hal yang paling penting karena meja merupakan tempat simpan berkas penting serta tugas-tugas yang dikerjakan menggunakan meja sebagai alas atau penunjang dalam bekerja, kesesuaian ini harus dilakukan demi meningkatkan kenyamanan pada saat karyawan bekerja, serta area penyusunan meja yang terjangkau sangat mempengaruhi produktifitas dan kesesuaian waktu dalam bekerja.

\section{PENUTUP}

\section{Kesimpulan}

Dari hasil yang telah dikemukakan pada bab empat, maka dapat ditarik kesimpulan dari hasil penelitian ini, yaitu :

a. Hasil analisis mengenai pengaruh Program CSR Internal menunjukan bahwa hasil analysis memiliki hubungan yang positif dan signifikan terhadap kepuasan Kerja Karyawan yang ditunjukan dengan koefisien variabel dimana pengaruh Program CSR Internal $\left(\mathrm{X}_{1}\right)$ bertanda positif dan signifikan terhadap Kepuasan Kerja Karyawan (Y) dengan nilai $\mathrm{t}_{\text {hitung }}$ sebesar 2.165 .

b. Hasil analisis mengenai pengaruh Lingkungan Kerja Fisik $\left(\mathrm{X}_{2}\right)$ memiliki hubungan yang positif dan signifikan terhadap Kepuasan Kerja Karyawan (Y) yang ditunjukan dengan koefisien variabel, dimana pengaruh Lingkungan Kerja Fisik bertanda positif dan memiliki pengaruh yang signifikan terhadap Kepuasan Kerja Karyawan dengan nilai $\mathrm{t}_{\text {hitung }}$ sebesar 2,361.

c. Variabel Program CSR Internal $\left(\mathrm{X}_{1}\right)$ dan Lingkungan Kerja Fisik $\left(\mathrm{X}_{2}\right)$ secara bersamasama memiliki pengaruh yang signifikan terhadap kinerja karyawan (Y). Dengan nilai F sebesar 4,363.

\section{Saran-saran}

Berdasarkan kesimpulan yang telah dikemukakan diatas, maka saran-saran yang dapat penulis berikan sebagai bahan masukan bagi perusahaan adalah sebagai berikut :

a. Dengan adanya pengaruh positif Program CSR Internal terhadap Kepuasan Kerja Karyawan, maka hendaknya pihak manajemen PT. Alex Putra Group terus menjaga 
pengaruh positif tersebut dengan selalu memberikan upaya kesejahteraan karyawan agar semangat kerja meningkat karena sedikit dari beban kehidupanya terbantu dan memberikan rasa loyalitas akan kenyamanan dalam bekerja untuk perusahaan.

b. Dengan adanya pengaruh positif pada Lingkugan Kerja Fisik terhadap Kepuasan Kerja Karyawan, maka hendaknya pihak manajemen PT. Alex Puttra Group selalu menjaga pengaruh positif tersebut guna memberikan Kepuasan Kerja Karyawan tetap dalam keadaan yang baik sehingga rasa loyalitas akan kenyamanan yang diberikan oleh perusahaan.

c. Dalam upaya meningkatkan Kepuasan Kerja Karyawan, pihak manajemen perusahaan sebaiknya mampu menerapkan berbagai program dan kebijakan dalam meningkatkan produktifitasa dan loyalitas karyawan misalnya pebuatan program dan rancangan yang matang perihal meningkatkan kesejahteraan dan kualitas hidup yang lebih baik, serta adanya kenyamanan dalam bentuk estetika pada lingkungan kerja fisik sebagai penunjang dalam bekerja sehingga mampu mendorong untuk menjadi lebih baik.

d. Bagi peneliti selanjutnya yang akan mengkaji lebih dalam pada bidang yangsama agar menambah faktor lain seperti promosi jabatan, pengawasan kerja,Pelatihan dan pengembangan karyawan, dan fasilitas yang memilikipengaruh terhadap kepuasan kerja karyawan sehingga dapat memberi kontribusi kepada PT. Alex Putra Group di Kota Cilegon khususnya dalam hal kepuasan kerja karyawan.

\section{DAFTAR PUSTAKA}

Arikunto,Suharsimi, 2010, Prosedur Penelitian Suatu Pendekatan Praktik, Rhineka Cipta, Jakarta.

Davis, Newstrom, 2012. Perilaku Dalam Organisasi, Edisi ketujuh, Jakarta ,Erlangga.

Handoko, T. H , 2008,Manajemen Personalia dan Sumber Daya Manusia, EdisiKedua, Yogyakarta: BPFE.

Hasibuan, M, 2006. Manajemen Sumber Daya Manusia. Jakarta, Bumi Aksara.

Kuncoro, Mudrajad dan Suhardjono. 2009, Manajemen Perbankan Teori danAplikasi, BPFE, Yogyakarta.

Mangkunegara, A. P. 2011, Manajemen Sumber Daya Manusia Perusahaan, Rosda, Bandung.

Mardiana.2005. Manajemen Produksi. Penerbit Badan IPWI, Jakarta, Prenhallindo.

Mardikanto. 2014. Corporate Social Responsibility. Alfabeta, Bandung

Panggabean. 2002. Manajemen Sumber Daya Manusia. Bogor. Ghalia Indonesia

Petkoski D, Twose N. 2003. Public policy for corporate social responsibility. Jointly sponsored by The World Bank Institute, the private sector development vice presidency of the world bank, and the international finance corporation. http://info.worldbank.org/July (diakses 10 Maret 2018).

Pohan. 2008. Corporate Social Responsibility. Yogyakarta : Graha Ilmu.

Robbins, Stephen P. dan Timothy A. Judge. 2008. Perilaku Organisasi Edisi ke12,Jakarta: Salemba Empat.

Sedarmayanti, 2006, Budaya Organisasi dan Peningkatan Kinerja, Jakarta, Bumi Aksara.

Situmorang, Syafrizal Helmi dan Paham Ginting. 2008. Filsafat Ilmu dan MetodeRiset.

Cetakan Pertama. Medan : USU Press.

Sugiyono, 2012, Metode Penelitian Bisnis, Alfabeta, Bandung. 
Veithzal, Rivai. 2005, Manajemen Sumber Daya Manusia. Jakarta : Raja Grafindo Persada.

\section{Jurnal :}

Ilona V,Oisina Situmorang, SD Purwaningsih. 2017. Program CSR dalam meningkatkankeberdayaan masyarakat Balongan (Kasus PT.Pertamina Refinery Unit VI Balongan). UPI-YAI. ISSN2580-5495

Nela PR, Bambang S, Arik P.2014. Pengaruh Lingkungan Kerja terhadap Kinerja Karyawan. (Studi Kasus Karyawan Pelayanan Pajak Pratama Malang Utara). JAB. UNBRAW Malang. Vol.8 No.2

Dhakiri, M. Hanifhttp://www.liputan6.com/news/read/3062714/program-csr-diharapkan-ikutpotong-rantai-kemiskinan

Eldaa, Alini. 2016. Pengaruh Lingkungan Kerja Fisik dan NonFisik terhadap Kinerja Karyawan pada KPPN Bandung I, Jurnal Sosioteknologi, Vol. 15, No 1.

Khairiyah, Nur Syaima. 2013. Pengaruh Kepuasan Kerja, Gaya Kepemimpinan,dan Motivasi Kerja Terhadap Kinerja Karyawan pada PT. Nutricia Indonesia Sejahtera, Proceeding PESAT (Psikologi, Ekonomi, Sastra, Arsitektur \& Teknik Sipil), Vol. 5.

Nela, Bambang, Arik. 2014. Pengaruh Lingkungan Kerja terhadap Kinerja Karyawan, Jurnal Administrasi Bisnis (JAB)| Vol. 8 No. 2.

Ratri, Ratnasari. 2012. Corporate Social Responsibility,Tanggung Jawab Sosial atau Strategi Perusahaan, Management Bussines, Vol. 1, hal. 4.

Suparman. 2013. Bentuk Tanggung Jawab Sosial dan Kepedulian Perusahaan dengan Masyarakat, magister Ilmu Komunikasi FISIP UNDIP, Jurnal Interaksi Vol. 2 No. 2.

Žana, Prutina. 2016. The Effect of Corprate Social Responsibility on Organizational Commitment, Management, Vol. 21, 2016, Special Issue, pp. 227-248. 